a community of origin being thereby probably indicated. M. P. Carrasco now points out (Comptes rendus, vol. clxi., p. 63I) that there is an additional member of this series, the next earlier term being the red line at $\lambda 6374 \cdot 2$. This line, unknown when Prof. Nicholson was pursuing his investigations, was the most important feature of the coronal spectrum as photographed at the late eclipse (August 2I, 1914), and M. Carrasco was one of the fortunate observers who obtained a record of the line.

Areas of Absorption Markings on SectrohelioGRAMS. - The results of the limb prominence observations made at Kodaikanal Observatory during the first half of the current year are given in Bulletin No. 47 . The mean daily area is the largest since 1908, and shows an increase of 59 per cent. over that for the preceding six months. Prominences seen projected on the disc as absorption markings on spectroheliograms taken in the light of the $\mathrm{H}_{\alpha}$ reversal are being specially recorded with the grating spectroheliograph for measurement. Mean daily areas in millionths of the sun's visible hemisphere and mean daily numbers for the five half-years $19^{12-13}$, and January-June, 1915, are published in the above bulletin. For the second half of I9I3 the areas were sixty, whilst for the first half of the present year they were 1375.6 . The distribution in latitude of these markings shows the prominence maximum between $50^{\circ}$ and $60^{\circ}$, together with a pronounced maximum about $30^{\circ}$, due to prominence in spot latitudes, the equator being avoided, as in the case of sun-spots.

\section{THE CORROSION OF METALS.}

$\mathrm{O}^{\mathrm{N}}$ December 8, under the presidency of Sir Robert Hadfield, the Faraday Society held a discussion on the corrosion of metals. Of the seven papers contributed, only two dealt with the more general aspects of this very important question. Three were concerned with the corrosion of iron, and some of the numerous steels which find application in modern industrial life; the remaining two had reference principally to marine condenser tube alloy, $70: 30$ brass. As it turned out, there was almost no discussion on the fundamental characteristics of corrosion phenomena. During the first hour instances of corrosion among iron alloys came under review, the remainder of the evening being devoted to a consideration of the corrosion of copper-zinc alloys.

As Dr. Rideal pointed out in his printed contribution to the more fundamental aspects of the question, "the phenomena observed in the corrosion of metals are to be found scattered among the earliest records of mankind, and in consequence of the universality of the subject we have received a heritage consisting of a jumble of facts and theories." The first report by Dr. Bengough to the Corrosion Committee of the Institute of Metals consists mainly of a critical examination of the views held with regard to the cause, or causes, of the corrosion of marine condenser tube alloy, the general conclusion being that the evidence is so conflicting that no particular view can be regarded as at all firmly established. The committee, therefore, in planning the experimental investigation decided that there was nothing for it but to begin at the very beginning and take nothing for granted.

Dr. Rideal's definition of corrosion is as follows :"Corrosion may be said to result from an irreversible chemical change proceeding with a small velocity and taking place on the common surfaces between two or more phases, the products of which change are continually removed from the sphere of action." Moreover, it takes place generally on the surfaces of phases which are electrically conducting, a fact which lies at the base of the now generally accepted electrolytic theory of corrosion. This theory requires the presence of minute cells operating on the surface of the corroded metal or alloy. As yet, however, there is no information as to the number of such cells or the rate at which they work.

Dr. Desch's contribution dealt with the influence of physical and mechanical factors in corrosion, an aspect of the subject the importance of which is by no means always adequately realised. Although the process of corrosion is probably in all cases initially one of chemical solution, the physical heterogeneity of the metal or alloy has a considerable influence on its nature and velocity. More especially has this to be considered when it is remembered that many of the commonly used industrial alloys are in a "strained" condition, and contain, as Dr. Beilby has shown, films of amorphous material on the surfaces of slip of the crystals. Such films have been demonstrated to be more electropositive than the crystalline material, a fact which determines the course of corrosion of cold-worked metals in particular. The increased corrodibility of such alloys is no doubt also partly to be ascribed to the energy produced by work being stored up in these films.

The Cumberland process for preventing the corrosion of metals immersed in liquids, of which a demonstration was given at the close of the discussion, is based upon a recognition of the galvanic nature of this phenomenon. It consists in introducing a higher counter-electromotive force to that causing the corrosive action. A continuous current working at ro volts is supplied to the anode, consisting of pieces of iron suspended in the liquid and insulated from the vessel being protected. It is claimed that this system has been in use in all types of steamships and in many large power plants, and that it is applicable to any metal in contact with water or any other corrosive liquid.

H. C. H. Carpenter.

\section{VISCOSITY OF OILS.}

THE Institution of Petroleum Technologists is one $I$ of the most recent of our technological associations. Founded in $19 \mathrm{I} 3$, to advance the study of mineral oils from the various points of view of the chemist, the geologist, the engineer, the prospector, and the financier, it has shown from the first a healthy vitality and the promise of a vigorous future. At a general meeting held on November 16 , at the Royal Society of Arts, the institution had the pleasure of listening to an illuminating address by Dr. Glazebrook on the viscosity of oils in relation to the rate of flow through pipes. The tests described had been undertaken at the request of the Admiralty, and permission had been given for their publication. The results of the investigation showed that the ordinary law of viscous flow, $\mathrm{P} / \mathrm{V}=2 \eta / 9 g d^{2}$, holds good in the particular case postulated so long as the critical velocity which is given in the expression $\rho \mathrm{Vd} / \eta=2500$ is not exceeded.

Many experimental difficulties were met with in the actual measurements, which were carried out in the engineering department of the National Physical Laboratory by Mr. Pannell. The small variations in pressure were measured by means of a sensitive mercury tilting gauge, and the quantity of oil passed per minute through the pipes was measured on an Avery weighing machine. Thermal changes were eliminated by jacketing and careful electrical heating.

In general excellent agreement was found between the calculated and observed values of $P / V$ through a wide temperature range.

Part ii. of the research was occupied with the determination of the physical contents of the various oils which were used. The densities call for little comNO. 2407 , vOL. 96] 
ment, the change in density being proportional to the change in temperature. The viscosities were determined in the Redwood I. and II. instruments, from which absolute values can be obtained by means of the relationship $\eta / \rho=\mathrm{AT}-\mathrm{B} / \mathrm{T}$, where $\mathrm{A}$ and $\mathrm{B}$ are calibration constants of the viscometer. The most marked observation in the viscosity results was the relatively enormous temperature coefficient exhibited by the Mexican fuel oils. Further, the results were shown to be dependent on the previous history of the oil. For example, an oil kept at $32^{\circ} \mathrm{F}$. for six days showed an increase in viscosity at $60^{\circ} \mathrm{F}$. amounting to 20 per cent., while a similar specimen, heated to $93^{\circ}$ F. for the same period, exhibited a decrease of II per cent. This hysteresis effect was shown to have considerable practical importance in the handling and utilisation of such oils. The viscosity of mixtures of Mexican and shale oils was described; the viscosityconcentration curves are not linear, but are sagged, and thus it happens that a relatively small addition of shale oil to Mexican oil causes a considerable decrease in the viscosity. Careful tests were also made respecting the flash points of the oils, and their mixtures. The observation was made that a bulk sample of oil flashed somewhat lower than the small amount used in the Gray instrument. These experiments were carried out by Mr. W. F. Higgins.

Dr. Glazebrook concluded by pointing out that much work remained to be done in connection with the physics and chemistry of the mixtures of complex bodies which constitute fuel oils.

\section{QUEENSLAND RAINFALL. ${ }^{1}$}

MR. H. A. HUNT, the Commonwealth MeteorI ologist, has in previous reports given concise histories of the rainfall for New South Wales and Victoria, the volume under notice being thus the third of the series to be published. This report contains all the available annual totals and number of days with rainfall recorded to the end of the year I9I3 for ro4o stations in Queensland, and in addition monthly values up to the end of I9I2 are given for I37 stations, so distributed as to afford a good representation over the area under consideration. Many of the records go back to I880, and even earlier, so that a good working basis is provided for investigators who require information in regard to local seasonal rainfall, or who may wish to compare the annual variations of rainfall in this part of Australia with those of the other States of the Commonwealth. Every effort was made to obtain trustworthy data, and in addition to the official records, all possible sources of information, such as histories of Queensland and old newspaper files, were searched. Much labour was involved in the elimination of discrepancies which so often appear when the same record is published in separate reports. A very useful appendix contains tables showing the monthly and yearly values of the meteorological elements (except wind direction and velocity) at Brisbane from I887 to I9I2.

The volume is copiously illustrated by maps and diagrams, among which may be mentioned twentyseven annual rainfall maps covering the period 1887 to I9I3, a map of mean annual rainfall, monthly normal rainfall maps, an interim rainfall map for Papua, and a frost map of Australia. Among the diagrams are several showing the height reached by various floods at the stations belonging to the hydrometric branch of the service, and graphs giving the

1 Meteorology of Australia. Commonwealth Bureau of Meteorology. Results of Raintall Observations made in Queensland, including all available Annual-Rainfall Totals'from IC40 Stations for all Years of Record up to ror 3 , together with Maps and Diagrams. Pp, 285. (Melbourne, 1914.). . Price Ios. $6 d$.

No. 2407 , VOL. 96] mean annual rainfall of the whole State of Queensland and its sub-divisions. An interesting chronological history of remarkable atmospheric occurrences fills 96 pages of the report, the data being discussed back to the middle of last century. It is worthy of note that only four displays of the Aurora Australis are on record, the cases observed occurring in the years 1869 , 1870, 1894, and 1909 .

For the twenty-six years, I888 to 1913, the mean annual rainfall for the whole State is 26.50 in., that of 1894 , the wettest year, 40.39 in., and of 1902 , the driest year, 12.63 in. The wettest year was thus $5^{2}$ per cent. above the average, while the driest year showed a defect of the same amount. In the fourteen years, 1892 to 1905 . only four exceeded the average, the disastrous effect of this long-continued drought being well shown in Diagram A, giving the total number of live stock, which fell from 27 millions in 1895 to Io millions in 1902, the decline being checked in 1903 by a rainfall in excess of the normal.

The large average rainfall map which accompanies the report shows that the maximum rainfall, indicated by the isohyet of 160 in., is centred in the vicinity of Harvey Creek (lat. $17^{\circ} \mathrm{S}$., long. $146^{\circ} \mathrm{E}$.), and that for about so miles north and south of this point a rainfall exceeding 70 in. falls on the coast and for some distance inland. An annual rainfall of $70^{\circ} \mathrm{in}$. is also found on the coast in four small patches located in latitudes $15^{\circ} \mathrm{S} ., 21^{\circ} \mathrm{S} ., 27^{\circ} \mathrm{S}$, and $28^{\circ} \mathrm{S}$. The smallest rainfall under ro in. occurs in the west and south-west of the State south of $23^{\circ} \mathrm{S}$.

It would have materially helped in the elucidation of the problems pertaining to rainfall distribution had the orographical features been indicated on this map. Queensland being in the monsoon region, the heaviest rains occur in summer, while the winter is usually quite dry.

The appearance in recent years of numerous memoirs dealing with Australian climatology is a marked tribute to the rapidly-growing activity and efficiency of the Commonwealth Service, the example of which in this respect will, we hope, be followed by other weather bureaux in the southern hemisphere.

R. C. M.

\section{CHEMISTRY OF FIRE AND} EXPLOSIVES.

I $\mathrm{N}$ a recent issue of the Revue Scientifique (September 25-October 9) Prof. A. Job has an interesting article upon the chemistry of fire and explosives. After considering the conditions for, and reactions during, ordinary combustion, the connection of explosion with combustion is described. It is pointed out that, in addition to the volume of gas evolved, heat developed, temperature attained, and pressure, another important factor remains, the rapidity of explosion. This leads to a distinction being drawn between explosives suitable for use as propellents, by reason of their progressive combustion, and what are termed in this country "high explosives," where the decomposition is initiated and propagated by shock (detonation). Mercury fulminate, nitrogen iodide, and lead azide are discussed as types of these sensitive detonating explosives. Fulminate is employed in detonators in France, lead azide being preferred in Germany, it being less sensitive to the decomposing action of moist heat.

As bursting charges for shells picric acid and trinitrotoluene are discussed, it being pointed out that whilst the former combines with metallic oxides, such as those of iron and lead, giving very sensitive compounds, and hence dangerous, the trinitrotoluene is free from this disadvantage. The higher melting 